\title{
Effect of Vitamin D Supplementation in Patients of Moderate Asthma Undergoing Treatment with Inhaled Corticosteroids
}

\author{
Rajendra Sharma $^{1^{*}}$, Sanjeev Kumar ${ }^{2}$, D. C. Dhasmana ${ }^{1}$ and Juhi Kalra ${ }^{1}$ \\ ${ }^{1}$ Department of Pharmacology, Himalayan Institute of Medical Sciences, Dehradun, Uttarakhand, \\ India. \\ ${ }^{2}$ Department of Pulmonary Medicine, Himalayan Institute of Medical Sciences, Dehradun, \\ Uttarakhand, India.
}

Authors' contributions

This work was carried out in collaboration between all authors. Author DCD designed the study and managed the analyses of the study. Authors RS and SK wrote the protocol and author RS performed

the statistical analysis and wrote the first draft of the manuscript. Author JK managed the literature searches. All authors read and approved the final manuscript.

Article Information

DOI: 10.9734/BJPR/2017/32843

Editor(s):

(1) Vasudevan Mani, Universiti Teknologi MARA (UiTM), Selangor, Malaysia.

Reviewers:

(1) Sarah Howe McKenna, Alberta Health Services, Calgary, Canada. (2) Rodrigo Nolasco dos Santos, Paulista School of Medicine, Federal University of São Paulo, São Paulo, Brazil. (3) Agnes Hamzaoui, Tunis El Manar University, Tunisia. Complete Peer review History: http://www.sciencedomain.org/review-history/19081

Original Research Article

Received $18^{\text {th }}$ March 2017 Accepted 6 $6^{\text {th }}$ May 2017 Published $16^{\text {th }}$ May 2017

\begin{abstract}
Background: Vitamin $\mathrm{D}$ is an essential nutrient with significant immunomodulatory effects. There is potential for a protective role of vitamin D against etiopathogenesis of asthma and morbidity. This study evaluated the effect of vitamin $D$ supplementation in patients with moderate asthma. Aims and Objectives: To evaluate the effect of vitamin D supplementation on lung function improvement in patients of moderate asthma undergoing treatment with inhaled corticosteroids. Materials and Methods: An interventional prospective study. A total of 60 patients of moderate asthma were enrolled in the study and randomly divided into two groups of 30 patients each. Group A: placed on steroid based treatment regimen (formoterol $6 \mu \mathrm{g}+$ budesonide $200 \mu \mathrm{g}$ ) + Vitamin D supplementation [60,000IU/week for 8 consecutive weeks]. Group B: placed on steroid based treatment regimen (formoterol $6 \mu \mathrm{g}+$ budesonide $200 \mu \mathrm{g}$ ) only, as control. The enrolled
\end{abstract}


patients were followed up for 12 weeks and assessed for various parameters of disease severity, asthma control and improvement in lung function by using asthma control test [ACT] questionnaire and Pulmonary function tests (spirometry). Collected data was analyzed using available statistical software [spss ver 20.0].

Results: Statistically significant changes $(\mathrm{P}<0.001)$ were seen in pre to post values of FEV1 [2.28 \pm 0.41 to $2.64 \pm 0.51]$, FVC [3.37 \pm 0.74 to $3.60 \pm 0.76$ ] and FEV1/FVC ratio [68.44 \pm 5.03 to 73.48 \pm 3.52 ] in Group A as well as in Group B i.e. FEV1 [2.28 \pm 0.48 to 2.64 \pm 0.52$]$, FVC [3.35 \pm 0.67 to $3.58 \pm 0.75$ ] and FEV1/FVC ratio [67.87 \pm 2.48 to $74.16 \pm 4.19]$. However there were no significant differences observed in pre and post values of FEV1, FVC and FEV1/FVC ratio in between the two groups.

Conclusion: Vitamin D supplementation failed to show additional benefits in lung function improvement in adults with moderate asthma undergoing treatment with inhaled corticosteroids in the present study.

Keywords: Asthma; vitamin D supplementation; inhaled corticosteroids; lung functions.

\section{INTRODUCTION}

Vitamin $D$ is a fat soluble vitamin which has shown numerous physiological effects and its role as an immune-modulator is suggested to be of great significance [1]. Vitamin $D$ can be obtained from dietary source (ergocalciferol or vitamin $D_{2}$ ) or else it can be synthesized by the skin under the influence of sunlight (cholecalciferol or vitamin $\mathrm{D}_{3}$ ). Inactivated form of vitamin $D$ gets activated within the body in two step activation process occurring in liver and kidney subsequently. Active form of vitamin D (calcitriol) binds to the vitamin D receptor (VDR), and then regulate gene expression after translocation to the nucleus. Alternatively, activated vitamin $D$ can bind to the VDR on the plasma membrane to exert rapid responses via production of second messengers [2].

The primary role of vitamin $D$ has been postulated for bone and calcium homeostasis however newer target identification have suggested its role in various pathophysiological condition like asthma, COPD, multiple sclerosis, ALS etc. There have been many studies of vitamin $D$ status and its association with asthma and allergy, although the results were contradictory. Some studies have demonstrated an association between vitamin $\mathrm{D}$ deficiency and increased asthma risk [3]. Similarly some other studies in children and adults reported that low levels of vitamin D were associated with asthma severity, altered lung function, increased airway hyper-responsiveness, increased reactivity to exercise, [4-10] and loss of control [11]. On the contrary, more time spent in the sun in winter between the ages of 6 and 15 years has been associated with an increased risk of hay fever [12]. There are several other studies that have reported no association between vitamin D status and asthma in either children or adults $[12,13]$.

Although the underlying mechanisms are not yet clear, it is proposed that vitamin $D$ enhances anti-inflammatory effect of corticosteroids in asthma, either by augmenting the production of IL-10 [14] or through inhibition of $\mathrm{TH}-17$ cytokine production $[15,16]$. On the other hand, low vitamin $D$ levels are suggested to cause a proinflammatory state. Moreover, vitamin D signalling pathways and receptor polymorphisms [17] can influence the balance between $\mathrm{TH}-1$ and $\mathrm{TH}-2[18,19]$ airway smooth muscle contraction and airway remodelling [20,21] all these factors have been implicated in asthma pathogenesis and severity. It is therefore suggested that vitamin D supplementation could modify steroid response and reduce airway inflammation leading to studies of vitamin $\mathrm{D}$ that might improve outcomes in patients with asthma $[14,15]$.

Asthma treatment guidelines recommend inhaled corticosteroids as the primary anti-inflammatory therapy for persistent asthma, however, significant variation in the responses of patients to inhaled corticosteroids have been observed $[22,23]$. Several factors could be responsible for such variation in response i.e. improper technique, treatment non-compliance, genetic susceptibility and some nutritional deficiency. Considering the aforementioned facts Variation in vitamin D status could also be one of the reason for variable treatment response. We hypothesized that vitamin D supplementation along with inhaled corticosteroids would improve the clinical efficacy of inhaled corticosteroids and will help in improving lung function in patients with moderate asthma. 


\section{MATERIALS AND METHODS}

This study was conducted in the department of pharmacology and pulmonary medicine, Himalayan Institute of Medical Sciences (HIMS), Swami Ram Nagar, Dehradun over a period of twelve months. Patients aged between $19-64$ years presented to pulmonary medicine OPD, HIMS, Dehradun with a primary diagnosis of moderate asthma were included in the study after obtaining written informed consent. The included patient were either non-smoker or exsmoker (stopped for >6years). The patient with acute respiratory tract infection, lung tumors \& other malignancies e.g. lymphoma etc., irreversible broncho-constriction i.e. COPD, interstitial lung disease, morphological anomaly i.e. kyphosis, scoliosis etc., cardiac arrhythmia, kidney dysfunctions, mal-absorption syndrome, pregnancy, calcium metabolism disorders and epileptic and seizure disorders were excluded in this study.

\subsection{Study Design}

It was an interventional prospective study. The patients fulfilling the inclusion criteria were recruited and randomly divided using random number table into two groups of 30 patients each. The enrolled patients were followed up for 12 weeks and they were assessed for various parameters of disease severity, asthma control at every 4 week study visit. The patient randomized to test arm (Group A) placed on steroid based treatment regimen (budesonide 200 $\mu \mathrm{g}$ +formoterol $6 \mu \mathrm{g}$ ) plus vitamin $\mathrm{D}$ supplementation in a dose of $60,000 / \mathrm{l} /$ week for 8 consecutive weeks. The patients randomized to control arm (Group B) were placed on steroid based treatment regimen (budesonide $200 \mu \mathrm{g}$ +formoterol $6 \mu \mathrm{g}$ ) only.

Patient details were taken in the case recording form. The symptoms and severity of the disease as well as level of asthma control of the patients were assessed by using ACT, Pulmonary function tests (Spirometry), and Biochemical parameters (e.g. IgE and vitamin D level and others as per discretion of the treating physician). Any serious adverse event (SAE) occurring during the study period were recorded using adverse event reporting form.

\subsection{Study Tools}

Asthma Control Test (ACT) [24]: Asthma control was assessed by self-reported Asthma Control Questionnaires, Asthma Control Test (ACT). The
ACT was a 5-item questionnaire that assessed interference with activity, shortness of breath, nocturnal symptoms, rescue medication use and self-rating of asthma control. Each item is scored using 1-5 scale and then summed (total score 525). A score of 20 or higher was found to be the most discriminating cut off to define well controlled asthma and a score lower than 15 was identified as the most discriminating cut-off to define asthma that was poorly controlled. ACT scores of 15-19 denotes not well-controlled asthma.

Pulmonary function test (PFT): Spirometry using Morgan HypAir Spirometer (P.K. Morgan Ltd, Rainham, UK) was performed to assess pulmonary functions i.e. FEV1, FVC and FEV1/FVC ratio. The testing was done in the sitting position, using a chair for safety reasons and nose clip was used to occlude the nostrils. Study patients were asked to put the tube in their mouth and to take a deep breath. Then study patients were asked to start blowing out hard and fast. They were encouraged to keep blowing for at least six second minimum or till the end of expiration. The spirometry examinations were repeated thrice for each study patient and finally one best measurement of three acceptable/reproducible trials was obtained. Thereafter to check the reversibility the bronchodilator drug was administered in the dose and by the method indicated for the test i.e. after a gentle and incomplete expiration, a dose of 100 $\mathrm{mcg}$ of salbutamol is inhaled in one breath from a valved spacer device. The breath was then held for $5-10$ s before the subject exhaled out. Four separate doses (total dose $400 \mathrm{mcg}$ ) were delivered at 30-s intervals. This dose ensured that the response was high on the salbutamol dose-response curve. Three additional acceptable tests were recorded $\geq 10 \mathrm{~min}$ and up to $15 \mathrm{~min}$ later for short-acting $\beta 2$-agonists and finally one best of the three trials was recorded. We considered post-bronchodilator values of FEV1, FVC and FEV1/FVC ratio for evaluation of lung functions of enrolled patients.

Adverse drug reactions (ADRs) reporting form as per Central Drugs Standard Control Organization (CDSCO) guidelines.

Serum vitamin $D$ level: Serum vitamin $D$ was estimated on VIDAS which was based on ELFA (Enzyme Linked Fluorescent Assay). The principle of assay combines an enzyme immunoassay competition method with a final fluorescent detection (ELFA). All instruction specified in the manual of The VIDAS $25 \mathrm{OH}$ 
Vitamin D TOTAL (bioMerieux SA, France) using the ELFA technique (Enzyme Linked Fluorescent Assay) was strictly followed. The samples were clarified by centrifugation. The calibrator, control and samples were mixed using a vortex-type mixer (for serum or plasma separated from the pellet). Bubbles were removed from samples, calibrators, controls and diluent before pipetting was done. For this test, the calibrator, control, and sample test portion was $100 \mu \mathrm{L}$. "VITD" SPRs and "VITD" strips were inserted into the instrument. The color labels with the assay code on the SPRs and the Reagent Strips would match. All the assay steps were performed on VIDAS which was an automated system based on ELFA. The assay was completed within approximately 40 minutes. Fluorescence was measured twice in the Reagent Strip's reading cuvette for each sample tested. The results were automatically calculated using calibration curves which were stored by the instrument (4parameter logistics model) and were expressed in $\mathrm{nmol} / \mathrm{L}$.

\subsection{Statistical Analysis}

Collected data was analyzed using available statistical software [spss ver. 20.0]. Qualitative data was expressed in the form of frequency and percentage and analyzed using chi-square test while the quantitative data was represented in the form of mean and standard deviation and analyzed using student t-test and RM-ANOVA.

\section{RESULTS}

A total of 72 patients screened for enrolment into the study. 12 patients were excluded or lost to follow up and finally a total of 60 patients enrolled and completed the study visits. The baseline demographic characteristics of the enrolled patient who have completed the study visits are given in Tables 1 and 2.

Statistically significant changes $(P<0.001)$ were seen in pre to post values of FEV1 $[2.28 \pm 0.41$ to $2.64 \pm 0.51]$, FVC $[3.37 \pm 0.74$ to $3.60 \pm 0.76$ ] and FEV1/FVC ratio [68.44 \pm 5.03 to $73.48 \pm 3.52]$ in Group A as well as in Group B i.e. FEV1 [2.28 \pm 0.48 to $2.64 \pm 0.52]$, FVC [3.35 \pm 0.67 to $3.58 \pm 0.75]$ and FEV1/FVC ratio $[67.87 \pm 2.48$ to 74.16 \pm 4.19$]$. However there were no significant differences observed in pre and post values of FEV1, FVC and FEV1/FVC ratio in between the two groups (Table 3 ).

Table 1. Comparison of baseline demographic characteristic

\begin{tabular}{|c|c|c|c|}
\hline Parameter & $\begin{array}{l}\text { Budesonide + Formoterol } \\
+ \text { Vitamin D arm N (\%) }\end{array}$ & $\begin{array}{l}\text { Budesonide + Formoterol } \\
\text { arm } N(\%)\end{array}$ & p-value \\
\hline \multicolumn{4}{|l|}{ Sex } \\
\hline Male & $16(53.3 \%)$ & $17(56.7 \%)$ & \multirow[t]{2}{*}{0.5} \\
\hline Female & $14(46.7 \%)$ & 13 (43.3\%) & \\
\hline \multicolumn{4}{|l|}{ Religion } \\
\hline Hindu & 28 (93.3\%) & $21(70 \%)$ & \multirow[t]{2}{*}{0.05} \\
\hline \multicolumn{3}{|l|}{ Food habits } & \\
\hline Vegetarian & 27 (90.0\%) & 19 (63.3\%) & \multirow[t]{2}{*}{0.01} \\
\hline Non vegetarian & $3(10.0 \%)$ & $11(36.7 \%)$ & \\
\hline \multicolumn{4}{|l|}{ Smoking status } \\
\hline Smoker & Nil & Nil & \\
\hline Non smoker & 28 (93.3\%) & 27 (90.0\%) & \multirow[t]{2}{*}{0.5} \\
\hline \multicolumn{3}{|l|}{ Family history } & \\
\hline Atopic & $5(16.7 \%)$ & $6(20.0 \%)$ & \multirow[t]{2}{*}{0.5} \\
\hline Non atopic & 25 (83.3\%) & $24(80.0 \%)$ & \\
\hline \multicolumn{4}{|l|}{ Drug history } \\
\hline Not Known & 27 (90.0\%) & 27 (90.0\%) & \multirow[t]{3}{*}{0.66} \\
\hline Positive & $3(10.0 \%)$ & $3(10.0 \%)$ & \\
\hline \multicolumn{3}{|l|}{ Personal history } & \\
\hline Married & $21(70.0 \%)$ & 21 (70.0\%) & \multirow[t]{2}{*}{1} \\
\hline Unmarried & $9(30.0 \%)$ & $9(30.0 \%)$ & \\
\hline
\end{tabular}


Table 2. Baseline parameters of lung function and disease severity

\begin{tabular}{llll}
\hline Parameter & $\begin{array}{l}\text { Budesonide + Formoterol + } \\
\text { Vitamin D arm (Mean } \pm S D)\end{array}$ & $\begin{array}{l}\text { Budesonide + Formoterol } \\
\text { arm (Mean } \pm \text { SD) }\end{array}$ & p-value \\
\hline Age $(\mathrm{yrs})$ & $36.37 \pm 11.27$ & $38.27 \pm 12.24$ & 0.53 \\
BMl $\left(\mathrm{kg} / \mathrm{m}^{2}\right)$ & $21.49 \pm 3.52$ & $22.45 \pm 4.74$ & 0.38 \\
Height $(\mathrm{cm})$ & $164.60 \pm 10.51$ & $162.97 \pm 8.84$ & 0.52 \\
Weight $(\mathrm{kg})$ & $58.33 \pm 11.14$ & $59.63 \pm 12.91$ & 0.68 \\
Vit D level (nmol/l) & $43.60 \pm 19.31$ & $37.45 \pm 15.53$ & 0.18 \\
FEV1 level (L) & $2.28 \pm 0.41$ & $2.28 \pm 0.48$ & 0.96 \\
FVC (L) & $3.37 \pm 0.74$ & $3.35 \pm 0.67$ & 0.92 \\
FEV1/FVC (\%) & $68.44 \pm 5.03$ & $67.87 \pm 2.48$ & 0.58 \\
\hline
\end{tabular}

Table 3. Improvement in lung function in the two study groups ( $n=30$ each group)

\begin{tabular}{|c|c|c|c|c|c|c|}
\hline \multirow[t]{2}{*}{ Parameter } & \multicolumn{3}{|c|}{$\begin{array}{c}\text { Budesonide + Formoterol + Vitamin } \\
\text { D arm }\end{array}$} & \multicolumn{3}{|c|}{ Budesonide + Formoterol arm } \\
\hline & $\begin{array}{l}\text { Baseline } \\
\text { (mean } \pm S D)\end{array}$ & $\begin{array}{l}\text { Week-12 } \\
\text { visit } \\
\text { (mean } \pm S D \text { ) }\end{array}$ & $\begin{array}{l}\mathrm{p}- \\
\text { value }\end{array}$ & $\begin{array}{l}\text { Baseline } \\
\text { (mean } \pm S D)\end{array}$ & $\begin{array}{l}\text { Week-12 } \\
\text { visit } \\
\text { (mean } \pm S D)\end{array}$ & $\begin{array}{l}\mathrm{p}- \\
\text { value }\end{array}$ \\
\hline $\begin{array}{l}\mathrm{FEV} 1 / \mathrm{FVC}(\%) \\
\text { ratio }\end{array}$ & $68.44 \pm 5.03$ & $73.48 \pm 3.52$ & $<0.001$ & $67.87 \pm 2.48$ & $74.16 \pm 4.19$ & 0.001 \\
\hline FEV1 (L) & 2.28 & 2.64 & م & 2.28 & 2.6 & $<0.001$ \\
\hline FVC (L) & $3.37 \pm 0.74$ & $3.60 \pm 0.76$ & $<0.001$ & $3.35 \pm 0.67$ & $3.58 \pm 0.75$ & $<0.001$ \\
\hline
\end{tabular}

We performed RM-ANOVA to evaluate the treatment effect at different time interval in the two treatment groups, however we did not observe any significant difference in the lung function improvement [Figs. 1, 2 and 3] between the groups whereas the improvement at last follow up visit [week-12 visit] from baseline was statistically significant within the treatment groups.

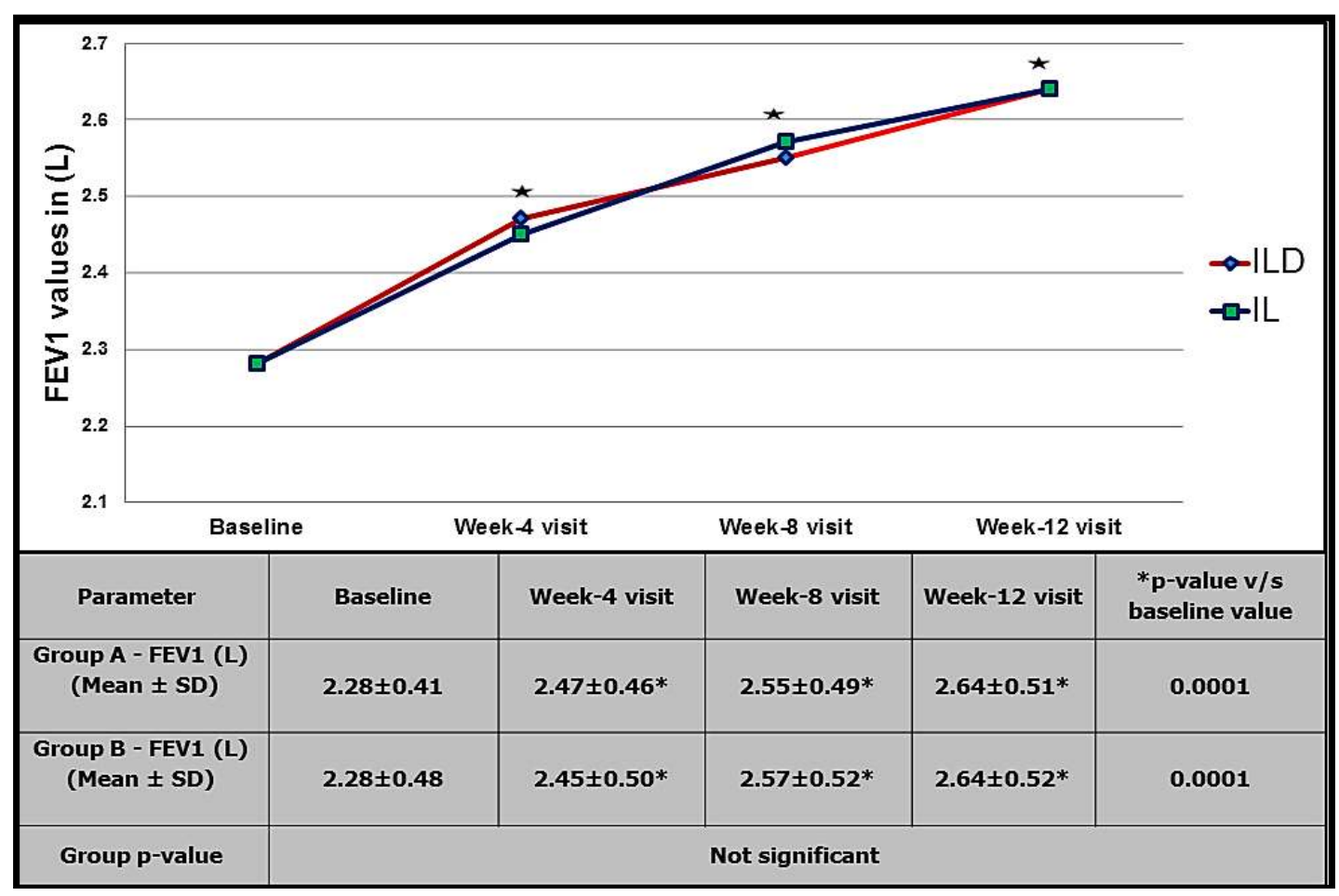

Fig. 1. Improvement in FEV1 (L) in two study groups ( $n=30$ each group) 


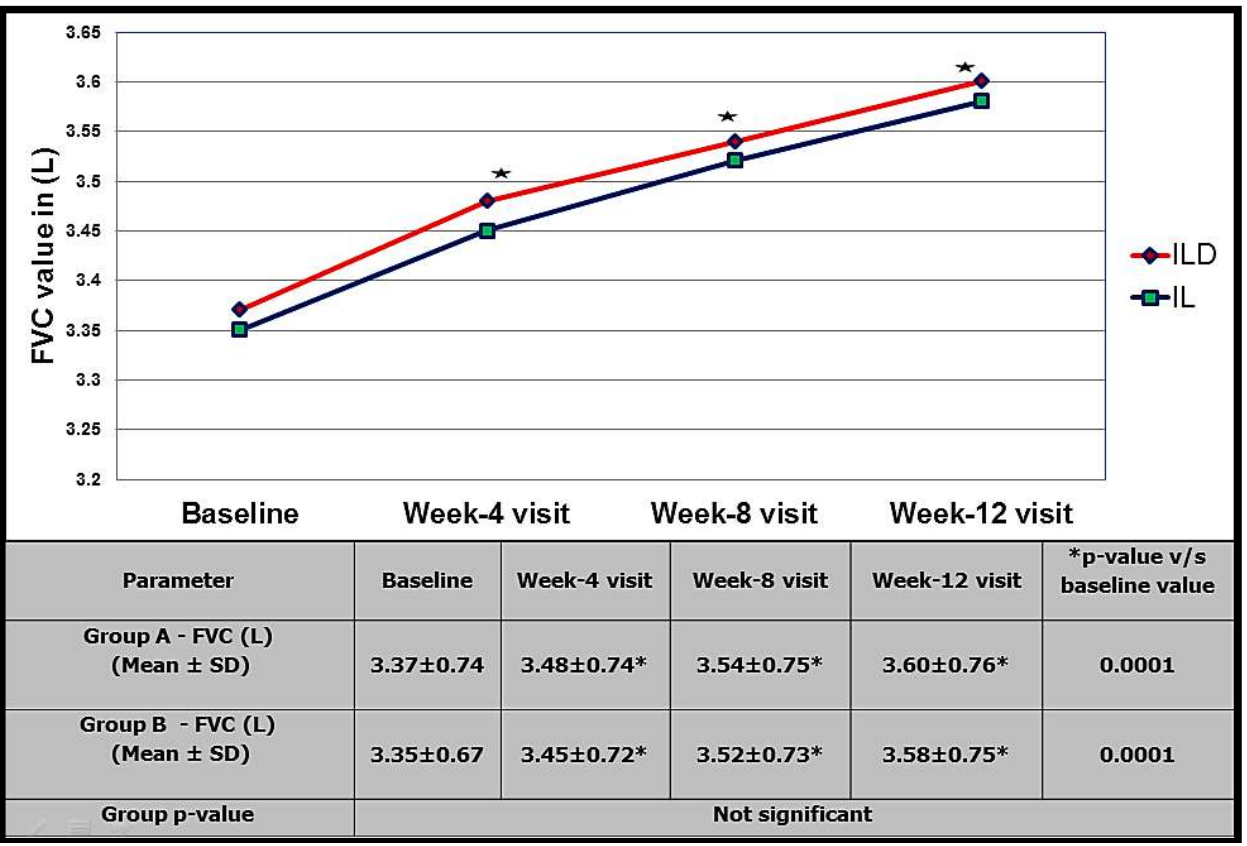

Fig. 2. Improvement in FVC (L) in two study groups ( $n=30$ each group)

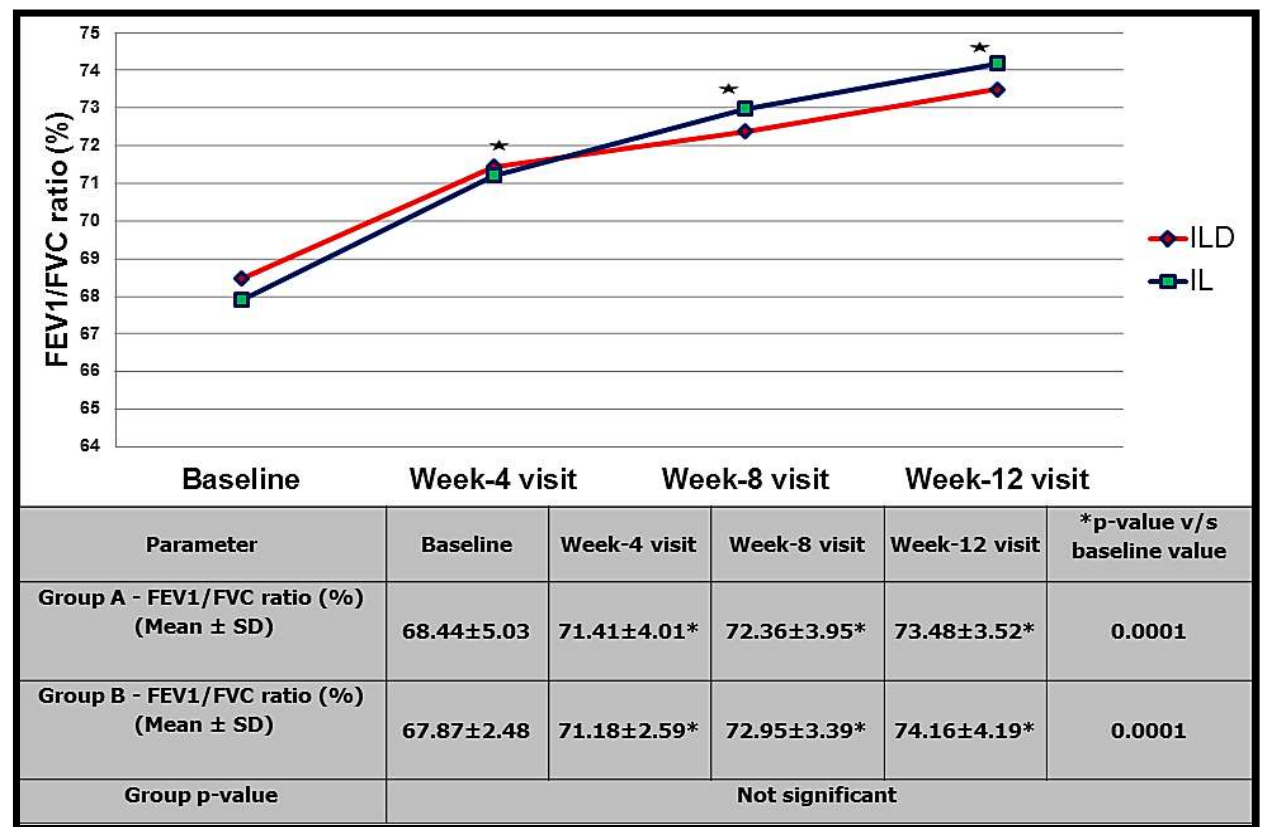

Fig. 3. Improvement in FEV1/FVC ratio (\%) in two study groups ( $\mathrm{n}=\mathbf{3 0}$ each group)

The correlation between the baseline vitamin $D$ patient was also assessed and the details of the level and baseline FEV1 of enrolled asthmatic association are depicted in Table 4.

Table 4. Correlation between baseline serum vitamin D level and FEV1 values

\begin{tabular}{llll}
\hline Parameters & $\begin{array}{l}\text { Budesonide + Formoterol + } \\
\text { Vitamin D arm }\end{array}$ & $\begin{array}{l}\text { Budesonide + Formoterol } \\
\text { arm }\end{array}$ & $\begin{array}{l}\text { Full cohort } \\
\text { altogether }\end{array}$ \\
\hline Vit D - FEV1 & 0.40 & 0.31 & 0.35 \\
\hline
\end{tabular}




\section{DISCUSSION}

Recently, several controlled clinical trials have been undertaken to explore the effect of vitamin D supplementation on asthma control and respiratory tract infections because asthma treatment continues to be a challenge in terms of symptom control and asthma related morbidity.

A study conducted by S. Arshi et al. [25] has shown beneficial effect of vitamin $D$ supplementation for 24 weeks along with the controller medication in asthmatic adults, although they did not observe any significant difference in clinical response at 8 week or earlier in this study. In our study we followed our patient for a period of 12 week and no significant difference $(p>0.05)$ between the groups was observed in lung function parameters on PFT at end of 12 week follow up period. We anticipated that shorter duration of vitamin $D$ supplementation against a background of vitamin $D$ deficiency in majority of patients can be a probable reason; why there was no significant difference observed between the two groups. However in the study conducted by S. Arshi et al. [25], significant difference in various parameters of PFT with higher doses of vitamin D supplementation i.e. 1,00,000IU intramuscular bolus and then 50,000IU/week for 24 weeks of treatment period was observed at completion of 24 weeks of follow up period only and it is postulated that relatively longer duration of follow up and supplementation of higher doses of vitamin $D$ could be a possible cause for the treatment response.

Interestingly, in a proof-of-concept study, Nanzer et al., reported that calcitriol $(1,25(\mathrm{OH}) 2 \mathrm{D} 3)$ as an add-on therapy to prednisolone for 4 weeks significantly improved the lung function in adults with corticosteroid-resistant asthma, indicating a rapid effect of calcitriol on augmenting corticosteroid responsiveness [26]. The augmentation of corticosteroid responsiveness may have been due to a common mechanism of action, acting via nuclear receptors.

On the other hand, a recently published study [27], Vitamin D Add-on Therapy enhances Corticosteroid Responsiveness in Asthma (VIDA) clinical trial, 408 patients with vitamin D insufficiency or deficiency on inhaled corticosteroids were randomized to receive addon therapy with placebo or high-dose vitamin D3 (100000IU loading dose followed by 4000 IU/day) for 28 weeks. The time to the first treatment failure (primary outcome), rate of first asthma exacerbation or overall exacerbation rate did not differ between vitamin D3 and placebo groups, although the overall dose of inhaled corticosteroids to maintain asthma control was slightly lower in those taking vitamin D3.In this 28 week study [27], vitamin D3 supplementation had no significant effect on lung function, $A H R$, asthma control, quality of life or sputum eosinophilia.

Furthermore, Vitamin D3 Supplementation in Adults with Asthma (ViDiA) trial [28] also evaluated the effect of vitamin D3 repletion on asthma exacerbation and upper respiratory infection. There was no significant difference in the time to severe exacerbation or upper respiratory infection with vitamin $\mathrm{D}$ compared with placebo [28].

In our study vitamin D3 supplementation alongwith budesonide+formoterol in patients with moderate asthma, did not result in additional improvement in the lung function. Although we observed a weak positive association ( $r=0.35)$ between vitamin D level and FEV1 at the baseline but this association could not be translated in lung function improvement with vitamin D supplementation. A number of possible explanations for the study observation can be postulated. Firstly, there could be various confounders and associated factors i.e. diet, variation in sun exposure timing, skin colour etc. which might have concealed the beneficial effects of vitamin $D$ in present study. It was also not clear whether the serum level of vitamin $D$ achieved in this trial, were the ideal vitamin $D$ levels needed in the pulmonary tissue for modulating inflammatory response. Moreover, while the total serum $25(\mathrm{OH})$ D3 concentration has been uniformly accepted as an indicator of vitamin $D$ status, the level of activated vitamin $D$ isoform [25 $(\mathrm{OH}) 2$ D3] and free bioavailable $25(\mathrm{OH})$ D3 would be of greater clinical significance and their levels are influenced by a genetic polymorphism. Secondly, although we assume increases in serum vitamin $D$ level after 8 weeks, there would be a wide range of vitamin $\mathrm{D}$ levels in the study population at this time point, suggesting that variable response to vitamin D3 may have occurred. The small sample size and short duration of follow up was also a limitation of the study and studies of larger sample size and longer duration will be needed to fully resolve the question of vitamin D3 efficacy on asthma. Further, although we did not observe any serious adverse events associated with vitamin D3 
treatment in our study, we cannot advocate routine vitamin $D$ supplementation in asthma beyond the current recommendation for vitamin D supplementation. Lastly, it has been alternatively hypothesized that low vitamin D status is the consequence rather than the cause of inflammatory disorders like asthma and longterm studies will be needed to shed further light on this issue.

\section{CONCLUSION}

Vitamin D supplementation failed to show additional benefits in lung function improvement in adults with moderate asthma undergoing treatment with inhaled corticosteroids in the present study.

\section{CONSENT}

As per international standard or university standard, patient's written consent has been collected and preserved by the authors.

\section{ETHICAL APPROVAL}

This study protocol was approved by Institutional Ethics committee of Himalayan Institute of Medical Sciences, Swami Rama Himalayan University, Dehradun [India].

All authors hereby declare that all experiments have been examined and approved by the appropriate ethics committee and have therefore been performed in accordance with the ethical standards laid down in the 1964 Declaration of Helsinki.

\section{DISCLAIMER}

Some part of this manuscript was previously presented and published in the following conference.

Conference name: Pharmaceutical Summit and Expo.

Dates: October 08-10, 2015.

Location: New Delhi, India.

Web Link of the proceeding:

https://www.omicsgroup.org/journals/23760419/2376-0419.C1.007-002.pdf

\section{ACKNOWLEDGEMENT}

We are grateful to all our teachers; Dr Girish Sindhwani, Dr Rakhi Khanduri, Mr Hemchandra
Sati for their help in design of the study, analysis of the data and help in recruiting the patient.

\section{COMPETING INTERESTS}

Authors have declared that no competing interests exist.

\section{REFERENCES}

1. Holick MF. Vitamin D deficiency. N Engl J Med. 2007;357:266-281.

2. Raby BA, Lazarus R, Silverman EK, et al. Association of vitamin D receptor gene polymorphisms with childhood and adult asthma. Am J Respir Crit Care Med. 2004;170(10):1057-1065.

3. Camargo CA Jr, Ingham T, Wickens $\mathrm{K}$, et al. Cord-blood 25-hydroxyvi- tamin D levels and risk of respiratory infection, wheezing, and asthma. New Zealand Asthma and Allergy Cohort Study Group Pediatrics. 2011;127:e180-e187.

4. Chinellato I, Piazza M, Sandri M, et al. Serum vitamin D levels and exerciseinduced bronchoconstriction in children with asthma. Eur Respir J. 2011;37:13661370.

5. Chinellato I, Piazza M, Sandri M, Peroni D, Piacentini G, Boner AL. Vitamin D serum levels and markers of asthma control in Italian children. J Pediatr. 2011;158:437441.

6. Burns JS, Dockery DW, Neas LM, et al. Low dietary nutrient intakes and respiratory health in adolescents. Chest. 2007;132: 238-245.

7. Black PN, Scragg R. Relationship between serum 25-hydroxyvitamin $D$ and pulmonary function in the third national health and nutrition exami- nation survey. Chest. 2005;128:3792-3798.

8. Sutherland ER, Goleva E, Jackson LP, Stevens $A D$, Leung DY. Vitamin D levels, lung function, steroid response in adult asthma. Am J Respir Crit Care Med. 2010;181:699-704.

9. Li $F$, Peng $M$, Jiang $L$, et al. Vitamin $D$ deficiency is associated with decreased lung function in Chinese adults with asthma. Respiration. 2011;81:469-475.

10. Searing DA, Zhang Y, Murphy JR, Hauk PJ, Goleva E, Leung DY. Decreased serum vitamin $D$ levels in children with asthma are associated with increased corticosteroid use. J Allergy Clin Immunol. 2010;125:955-1000. 
11. Poon AH, Mahboub B, Hamid Q. Vitamin D deficiency and severe asthma. Pharmacol Ther. 2013;140:148-155.

12. Hughes AM, Lucas RM, Ponsonby AL, et al. The role of latitude, ultraviolet radiation exposure and vitamin $D$ in childhood asthma and hayfever: An Australian multicenter study. Pediatr Allergy Immunol. 2011;22:327-333.

13. Devereux G, Wilson A, Avenell A, McNeill G, Fraser WD. A case- control study of vitamin $D$ status and asthma in adults. Allergy. 2010;65:666-667.

14. Xystrakis E, Kusumakar S, Boswell S, et al. Reversing the defective induction of IL10-secreting regulatory $\mathrm{T}$ cells in glucocorticoid-resistant asthma patients. J Clin Invest. 2006;116(1):146-155.

15. Nanzer AM, Chambers ES, Ryanna K, et al. Enhanced production of IL-17A in patients with severe asthma is inhibited by 1a,25- dihydroxyvitamin D3 in a glucocorticoid- independent fashion. J Allergy Clin Immunol. 2013;132(2):297304, e3.

16. Joshi S, Pantalena LC, Liu XK, et al. 1,25dihydroxyvitamin $\mathrm{D}(3)$ ameliorates Th17 autoimmunity via transcriptional modulation of interleukin-17A. Mol Cell Biol. 2011;31(17):3653- 3669.

17. Poon $A H$, Laprise $C$, Lemire $M$, et al. Association of vitamin $D$ receptor genetic variants with susceptibility to asthma and atopy. Am J Respir Crit Care Med. 2004;170(9):967-973.

18. Wittke A, Chang A, Froicu M, et al. Vitamin $D$ receptor expression by the lung microenvironment is required for maximal induction of lung inflammation. Arch Biochem Biophys. 2007;460(2):306-313.

19. Cantorna MT. Vitamin $D$ and its role in immunology. Prog Biophys Mol Biol. 2006;92(1):60-64.

20. Banerjee A, Damera G, Bhandare R, et al. Vitamin $D$ and glucocorticoids differentially modulate chemokine expression in human airway smooth muscle cells. $\mathrm{Br} J$ Pharmacol. 2008;155(1):84-92.
21. Song $\mathrm{Y}$, Qi $\mathrm{H}, \mathrm{Wu}$ C. Effect of 1,25(OH)2D3 (a vitamin D analogue) on passively sensitized human airway smooth muscle cells. Respirology. 2007;12(4):486494.

22. Malmstrom K, Rodriguez-Gomez G, Guerra J, et al. Oral montelukast, inhaled beclomethasone, and placebo for chronic asthma. Ann Intern Med. 1999;130(6):487495.

23. Szefler SJ, Martin RJ, King TS, et al. Significant variability in response to inhaled corticosteroids for persistent asthma. J Allergy Clin Immunol. 2002;109(3):410418.

24. US Department of Health and Human Services, National Institutes of Health, National Heart, Lung, and Blood Institute. Expert Panel Report 3: Guidelines for the Diagnosis and Management of Asthma (EPR-3 2007).NIH Item 08-4051. [Cited 2013 Oct 10].

Available:http://www.nhlbi.nih.gov/guidelin es/asthma/asthgdln.htm.

25. Arshi S, Fallahpour $M$, Nabavi $M$, Bemanian MH, Mousavi Sayed AJ, Nojomi $M$, et al. The effects of vitamin D supplementation on airway functions in mild to moderate persistent asthma. Ann Allergy Asthma Immunol. 2014;113:404-9.

26. Nanzer AM, Chambers ES, Ryanna K, et al. The effects of calcitriol treatment in glucocorticoid-resistant asthma. J Allergy Clin Immunol. 2014;133:1755-7.

27. Castro M, King TS, Kunselman SJ, Cabana MD, Denlinger L, Holguin F, et al. Effect of vitamin D3 on asthma treatment failures in adults with symptomatic asthma and lower vitamin $D$ levels the vida randomized clinical trial. J Am Med Assoc. 2014;311:2083-91.

28. Martineau AR, MacLaughlin BD, Hooper $\mathrm{RL}$, et al. Double-blind randomised placebo-controlled trial of bolus-dose vitamin D3 supplementation in adults with asthma (ViDiAs). Thorax. 2015;70:451-7.

(c) 2017 Sharma et al.; This is an Open Access article distributed under the terms of the Creative Commons Attribution License (http://creativecommons.org/licenses/by/4.0), which permits unrestricted use, distribution, and reproduction in any medium, provided the original work is properly cited.

Peer-review history:

The peer review history for this paper can be accessed here: http://sciencedomain.org/review-history/19081 